Western University Scholarship@Western

1979

\title{
Simultaneity and the Demand for Money in Canada
}

Stephen S. Poloz

Follow this and additional works at: https://ir.lib.uwo.ca/economicsresrpt

Part of the Economics Commons

Citation of this paper:

Poloz, Stephen S.. "Simultaneity and the Demand for Money in Canada." Department of Economics Research Reports, 7920. London, ON: Department of Economics, University of Western Ontario (1979). 
ISSN : $\quad 0318-725 \mathrm{X}$

ISBN : $\quad 0-7714-0117-5$

RESEARCH REPORT 7920

SIMULTANEITY AND THE DEMAND FOR MONEY

IN CANADA

by

Stephen S. Poloz

Ju1y, 1979 
Simultanelty and the Demand for Money in Canada*

by

\author{
Stephen S. Poloz \\ Department of Economics \\ University of Western Ontario \\ London, Canada
}

N6A $5 \mathrm{C} 2$

* I should like to thank Richard Beaulieu, Kevin Clinton, Joel Fried, Peter Howitt, David Laidler, Kevin Lynch, and Aman Ullah for helpful comments and suggestions. The errors which remain, of course, are the responsibility of the author. 


\section{Introduction}

The relevance of the issue of simultaneous equations bias in respect of the Canadian demand for money function is beyond dispute. If, for any reason, national income or particularly the rate of interest were correlated with the error term of the estimating equation, the ordinary least squares (OLS) or generalised least squares (GLS) estimates of the elasticities would be biased. This would cause the Bank of Canada to systematically err in Its estimate of the response of the money stock to a proposed change in the rate of interest.

There is reason to believe that this problem is virtually non-existent In the Canadian data. The reason is simply that the traditional approach to monetary policy in Canada has been to accommodate money demand so as to yield a relatively stable rate of interest. If the latter has been set exogenously, no correlation between the rate of interest and the regression residual can occur, so there will be no simultaneous equations bias. This view has been aptly expressed by White (1976, pp. 90-91):

... It is doubtful that such a problem exists with Canadian data. Until recently there was virtually no suggestion in the published literature of the Bank of Canada that narrow monetary aggregates were (or should be) intermediate targets for policy. The focus of discussion has been primarily on the cost and availability of credit.

Treating the rate of interest as endogenous, White has gone on to describe the results of a comparison between OLS and instrumental variables (IV) estimates of the demand for money equation. These he found to be virtually identical. 1 
A number of counter-arguments exist, however, which would lead one to expect contrary results. In particular, the following argument has been made by Laldler (1977, pp. 143-144) in respect of the popular partial-adjustment model of money demand. Briefly, it would seem that unlike an individual, the economy as a whole cannot "adjust" slowly towards its equilibrium holding of cash balances. If the money stock is exogenously given, it must be held. Thus, if the current money stock is not that desired by the economy as a whole, the arguments of the money demand function must change in order to induce the economy to hold the cash. If the Bank of Canada were following a policy regime wherein the actual money stock were systematically different from the desired money stock, adjustments in the interest rate and income variables would become correlated with the regression residuals and simultaneous equations bias would result.

This argument has been carried to the extreme by Artis and Lewis (1976), who have postulated that in the short-run money demand function the only endogenous variable is the rate of interest. This has led them to fit a partial-adjustment model of the rate of interest--that is, to fit their money demand equation with the rate of interest as the dependent variable. The model performs very well for the British data, but experimentation with this model on the Canadian data has yielded results which are not worth reporting here. 2

The above argument is precluded, however, if the Bank of Canada has been willing and able to accommodate the demand for money in the short run regardless of what state of adjustment the economy may be in. Under a system of fixed exchange rates, as was the case in Canada from 1962 to 1970, the 
supply of money must be demand-determined, except in the very short run. Under a floating exchange rate regime, however, the Bank's ability and willingness to accommodate are open to question.

First, the precision with which the Bank of Canada can achieve a neutral cash setting is questionable (c.f. Dingle, Sparks and Walker, 1972) since the level of excess cash reserves desired by the banking system in any given period is difficult to estimate, but this phenomenon would be difficult to detect in data which had been averaged up to monthly, or quarterly observatIons. On the other hand, the willingness of the Bank to accommodate money demand will, in general, depend upon the Bank's intermediate goals. Since 1970 these goals have ranged from (c.f. Courchene, 1976, 1977) (a) attempting to pull the Canadian economy out of the $1969-70$ recession, while holding down the value of the newly-floated dollar, (b) attempting to gradually wind down the growth in the money stock by setting growth targets for Ml (1975 to. present) and (c) combining (b) with an attempt to slow the decline of the dollar (1977 until recently).

The thrust of the above arguments is that the extent of simultaneity in the Canadian demand for money function ought to be varlable and dependent upon the particular policy regime in force. Thus, the issue of simultaneity in the money demand function cannot be resolved by simply estimating the equation in two ways and comparing; sub-sample analysis is clearly necessary. This, then, is the purpose of the following exercise. 
1. The Model and Data

In order to analyze the issue of simultaneity in respect of the demand for money, I have employed the simple but popular partial-adjustment model of money demand. ${ }^{3}$ In logarithms this model is given by:

$$
\begin{aligned}
& \text { (1.1) } \mathrm{m}_{t}^{*}=\beta_{0}+\beta_{1} y_{t}+\beta_{2} r_{t}+\text { seasonal factors } \\
& \text { (1.2) } \mathrm{m}_{t}-\mathrm{m}_{t-1}=\lambda\left(\mathrm{m}_{t}^{*}-\mathrm{m}_{t-1}\right)+\varepsilon_{t} .
\end{aligned}
$$

where $m_{t}$ is the logarithm of real cash balances, $y_{t}$ is the logartthm of real current income, $r_{t}$ is the logarithm of the rate of interest, and the asterisk denotes a desired equilibrium level. Combining equations (1.1) and (1.2) yields the estimating equation:

$$
\text { (1.3) } \mathrm{m}_{t}=\lambda \beta_{0}+\lambda \beta_{1} \mathrm{y}_{t}+\lambda \beta_{2} \mathrm{r}_{t}+(1-\lambda) \mathrm{m}_{t-1}+S F^{\prime} \mathrm{s}+\varepsilon_{t} \text {. }
$$

It should be pointed out that equation (1.3) is non-1inear in the long-run elasticities $\beta_{1}$ and $\beta_{2}$; however, these are just-identifiable in $\lambda$ so the equation may be treated as linear.

For the purposes of IV estimation, both the rate of interest and the level of income were treated as endogenous, and the instruments used were (a) a constant term and three seasonal dummy variables, (b) the lagged money stock, (c) the level of exports, (d) the level of government expenditure and (e) the rate of interest on 90-day U.S. Treasury B111s. The data are quarterly, and seasonally unadjusted, 1956I to 1978IV; explicit data sources 


$$
-5-
$$

are given at the end of the paper. The definition of money relevant to the issue at hand is taken to be Ml (currency plus non-government demand deposits) as this is the aggregate toward which Bank of Canada policy is and has been directed. The rate of interest used is that on 90-day financial company paper (the commercial paper rate) while GNE is the income variable. All varlables are in real logarithms; the money stock is deflated using the Implicit GNE deflator.

\section{Empirical Results}

The results of estimating equation (1.3) using OLS and IV estimation are given in Table 2.1 (standard errors are given in parentheses).

Table 2.1

Full-Sample Estimation

$\underline{\text { OLS }} \underline{\text { IV }} \quad \underline{\text { Bias }}$

Impact Elasticities

$\begin{array}{lccc}\lambda \beta_{1} & 0.216(.034) & 0.201(.041) & 0.015(7.46 \%) \\ \lambda \beta_{2} & -0.054(.009) & -0.049(.012) & -0.005(10.20 \%) \\ 1-\lambda & 0.704(.057) & 0.724(.068) & -0.020(2.76 \%)\end{array}$

Long-Run Elasticities

$\begin{array}{llll}B_{1} & 0.730(.036) & 0.728(.067) & 0.002(0.27 \%) \\ B_{2} & -0.182(.044) & -0.178(.061) & -0.004(2.25 \%)\end{array}$


Table 2.1 (Continued)

$\underline{\text { OLS }} \underline{\text { IV }} \quad \underline{\text { Bias }}$

Statistics

$\begin{array}{ccc}\mathrm{R}^{2} & .992 & .992 \\ \text { SSR } & .026 & .026 \\ \text { DW } & 2.13 & 2.18 \\ \text { rbin } \mathrm{h} & 0.74 & 1.10 \\ \mathrm{IS}_{4} & 1.50 & 1.48\end{array}$

The summary statistics indicate that there is nothing to distinguish the two equations. Both fit extremely well, and exhibit no first-order serial correlation by the Durbin $h$ statistic. Furthermore, the Wallis $\mathrm{D}_{4}$ statistics (Wallis, 1972) Indicate that there may be some small degree of fourth-order serial correlation, but both statistics are very near the inconclusive region so that this difficulty will be ignored.

A comparison between the OLS and IV estimates of the parameters indicates that the extent of simultaneous equations bias was, on average, very small over the sample period. Indeed, the extent of bias is always less than the standard error of the particular parameter. However, this is an average for the perlod taken as a whole, and I have argued above that the extent of simultaneity might be expected to vary through time.

In order to test the latter proposition, I proceeded to estimate the two equations recursively; that is, first estimating the equations using the first $k$ observations, where $k$ is the number of regressors, then the first $k+1$ observations, and so on, extending the regression line until all observations were used. At each step, a new estimate of the parameters was obtained, until 
the last estimate was that given in Table 2.1. A plot of the sequence of coefficients should then reveal any trends or shocks which exist in the data. This method of examining a regression has been suggested by Brown, Durbin and Evans (1975).

Figure 2.1 plots the long-run elasticities for the oLs recursive regression, while Figure 2.2 does the same for the IV recursive regression. Note that at each step the latter uses only the Information available up to that point, both in the first and second stages of estimation.

The similarity of the two plots should not be surprising, given the similarity between the two sets of results shown in Table 2.1. Note that neither plot, but particularly the IV one, should be interpreted early in the sample--the irregularity there is due to the small number of observations which are avallable. However, there is some evidence of a shock in 1962, as detected in a previous paper (Poloz, 1979); elsewhere, the coefficients are relatively smooth. There does seem to be a gradual upward trend in the income elasticity up until 1974II, after which a downward trend is observed. The movement in the interest elasticity is exactly opposite to that of the income elasticity. The movements after 1974 indicate that the money demand function did indeed shift downward somewhat. This problem was evidently noticed by the Bank of Canada during 1976 (c.f. Courchene, 1977, pp. 94-95).

The logical step to undertake next was to calculate the percentage difference between the IV and OLS elasticity estimates at each stage of the recursive regressions. A plot of the percentage bias in the two long-run elasticities is given in Figure 2.3. 


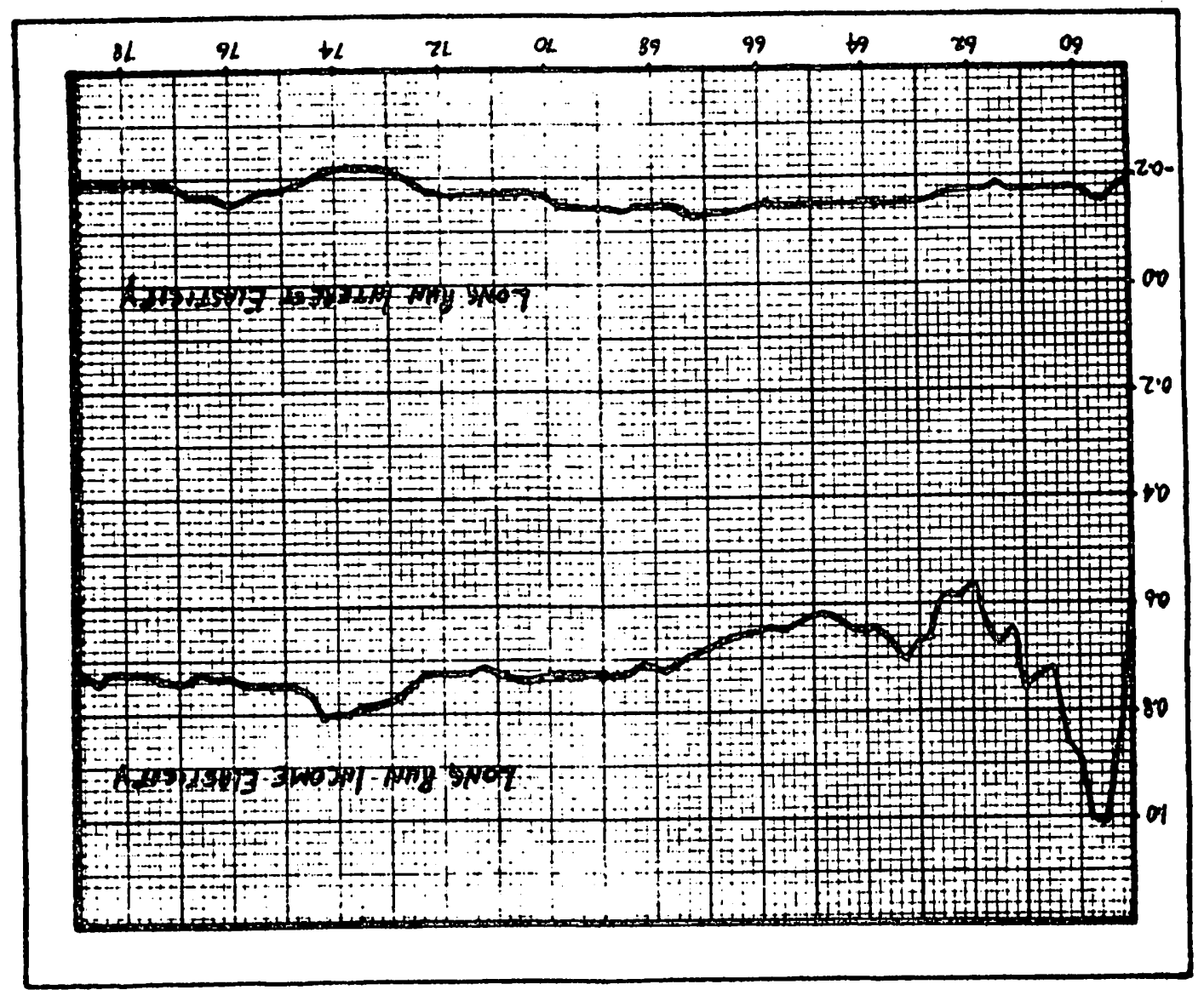

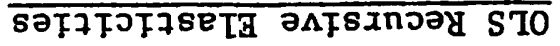

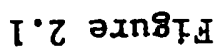


Figure 2.2

\section{Recursive Elasticities}

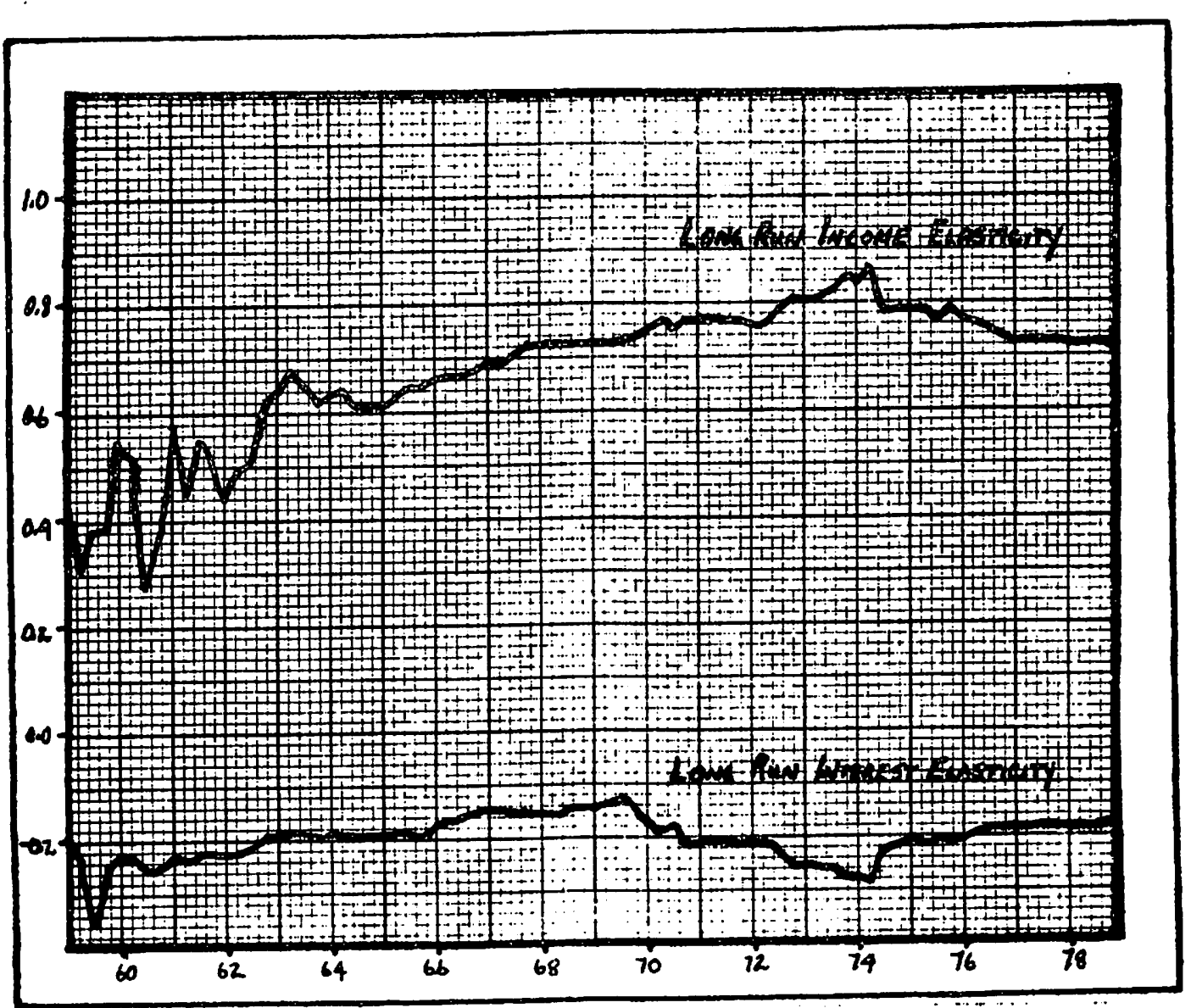


Figure 2.3

Recursive Percentage Blas of OLS Estimates

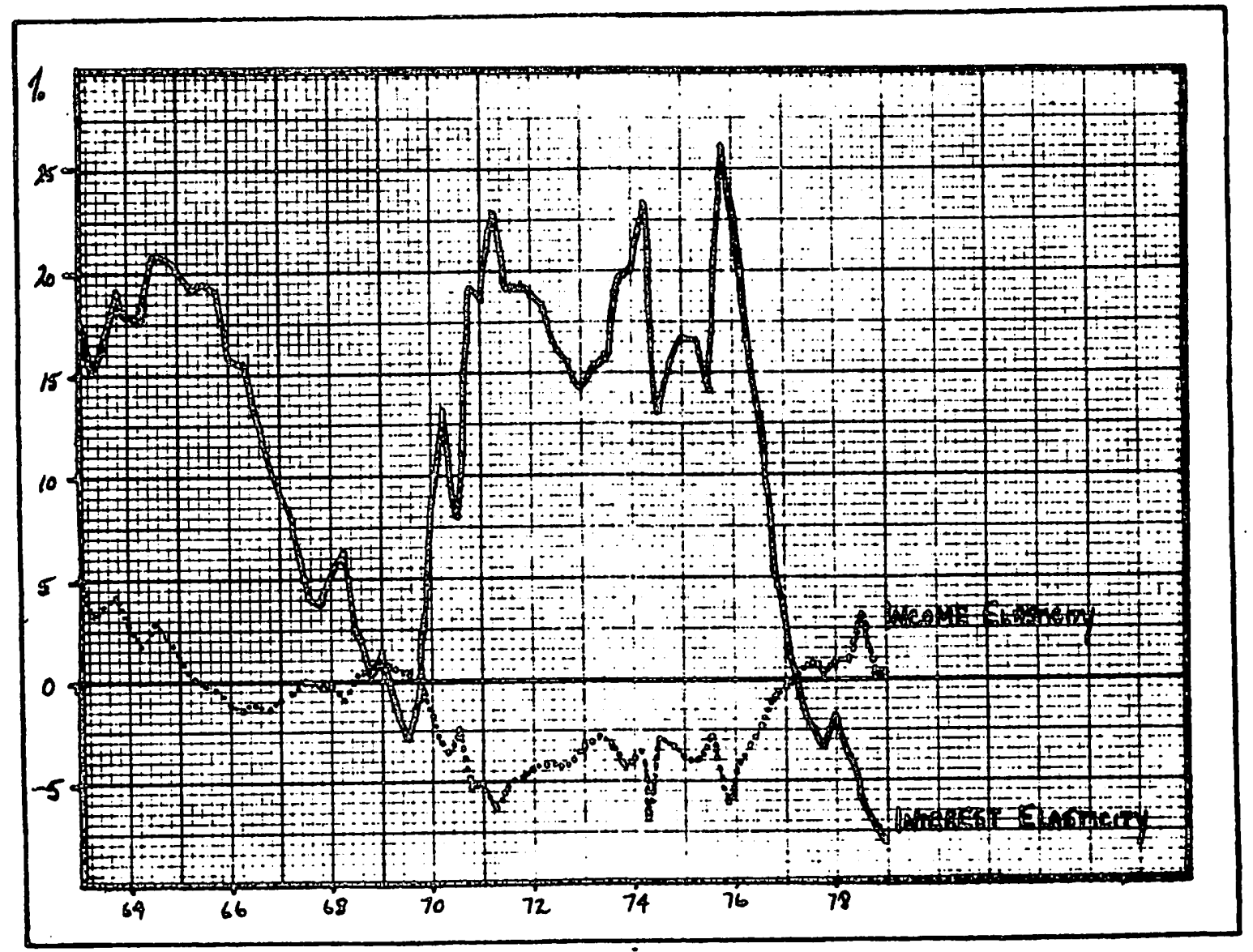


The two plots in Figure 2.3 are extremely revealing; the turning points are precisely identifiable with changes in monetary policy regimes In Canada.

First, recall that from 1962 II to 1970 II Canada was on a fixed exchange rate regime. Assuming that the plots are reliable from, say, 1966 onwards (forty observations), we see that the extent of simultaneous equations bias in either elasticity is near zero. In 1970II Canada moved to a floating exchange rate, and monetary policy switched immediately from highly restrictive sterilization to an extremely expansionary stance (c.f. Courchene, 1976, ch. 7). Evidently this led to a period of time during which the actual money stock was systematically greater than that desired by the economy, for the simultaneous equations bias in the interest elasticity becomes positive, averaging near twenty percent, while the bias in the income elasticity becomes negative. Furthermore, this situation persists until mid-1976, at which time growth in the money stock began to fall in response to the setting of growth targets for M1 (c.f. Courchene, 1977, p. 81, Figure 1). At this time, the bias in both elasticities once again approaches zero, and then each blas reverses its sign at 1977II. Thus, it is evident that the actual money stock has been systematically less than the desired money stock since that time. More observations will be required before a positive analysis may be performed after this point; however, it would seem likely that insofar as the adoption of target growth rates for $\mathrm{Ml}$ constrains the demand for money, the negative trend which is beginning now in the case of the interest elasticity would be expected to continue. 
It is reassuring to note that the extent of bias under discussion is still very small, even during the 1970-1975 period. However, the trends which have been observed are unmistakably due to Bank of Canada policy, and this implies that simultaneous equations bias in the OLS money demand regression is likely to be non-zero during the current and ongoing period of monetary restraint.

\section{Conclusion}

I began by analyzing the mechanism by which simultaneous equations blas might appear in the Canadian demand for money function. The resulting hypothesis, that this bias would be expected to change through time according as the extent to which Bank of Canada monetary policy has been nonaccomodating of money demand, has been strongly confirmed by the data. Although the extent of bias has typically not been large in absolute terms, that in the interest elasticity has of ten exceeded twenty percent. This would lead the Bank to err by this same percentage in its estimate of the response in $M 1$ to a proposed change in the rate of interest. Furthermore, the current and ongoing period of monetary restraint is 1ikely to witness a new increase in the extent of simultaneous equations bias, but in a pattern opposite to that experienced during the 1970-1975 period of monetary expansion. 


\section{Footnotes}

1 This result, of course, must be conditioned upon White's choice of instruments. I would agree with his choices with one exception--he uses the lagged rate of interest as an instrument. Strictly speaking, this is a correct procedure, but given that there is the likelthood of serial correlation in the interest rate series (espectally since White is using monthly data) the inclusion of this instrument tends to defeat the purpose behind IV estimation.

This model yields an estimating equation of the form:

$$
r_{t}=\alpha_{0}+\alpha_{1} y_{t}+\alpha_{2} m_{t}+\alpha_{3} r_{t-1}+\varepsilon_{t} .
$$

For the quarterly data 1956-1978 (as defined below) only $\alpha_{3}$ is significant. Furthermore, the equation is highly serially correlated; since the equation which I use below is not, this implies that the above model may be misspecified. This does not mean that the model may not be appropriate during a particular period. However, I do not think that the extent to which Artis and Lewis carry the argument is correct, in any event. I would prefer to interpret the reasoning as support for the need to use a simultaneous estimation technique on the traditional form of the money demand equation.

3 The partial-adjustment model was not chosen without some experimentation with other models. In particular, the Artis-Lewis model (c.f. footnote 2 above), a permanent income-error-learning model, a model which allowed lagged response to prices, and the classical full-adjustment model were experimented with. When estimated over the entire sample, the behaviour of the partialadjustment model in terms of $f i t$, serial correlation, and parameter estimates surpassed these four. I would like to thank Professor David Laidler for pointing out to me the importance of considering alternatives to the partialadjustment model. 


\section{References}

Artis, M.J. and M.K. Lewis (1976), "The Demand for Money in the United Kingdom: 1963-73," Manchester School, 44, 2.

Brown, R.L.; Durbin, J.; and J.M. Evans (1975), "Techniques for Testing the Constancy of Regression Relationships Over Time," Journal of the Royal Statistical Society, Series B.

Clinton, K. (1976), "A Note on the Implications for Estimating M1 Equations of Policies Aimed at Controlling Ml," Bank of Canada Mimeo.

Courchene, T.J. (1976), Money, Inflation, and the Bank of Canada, C.D. Howe Research Institute, Montreal.

- (1977), The Strategy of Gradualism, C.D. Howe Research Institute, Montreal.

Dingle, J.F.; Sparks, G.R.; and M.A. Walker (1972), "Monetary Pollcy and the Adjustment of Chartered Bank Assets," Canadian Journal of Economics, v, 4 .

Laidler, D.E.W. (1977), The Demand for Money: Theories and Evidence, Second Edition, Dun-Donnelley, New York.

Poloz, S.S. (1979), "The Stability of the Demand for Money in Canada 19521977," Institute for Economic Research, Queen's University, Discussion Paper No. 323.

Wali1s, K.F. (1972), "Testing for Fourth-Order Autocorrelation in Quarterly Regression Equations," Econometrica, 40.

White, W.R. (1976), "The Demand for Money in Canada and the Control of Monetary Aggregates: Evidence from the Monthly Data," Bank of Canada Staff Research Study No. 12. 
$-15-$

Data Sources

All data are from the CANSIM data bank.

\section{SERIES}

Real GNE

Government Expenditure

Exports

M1

Commercial Paper Rate

U.S. Treasury B111 Rate

Nominal GNE
CANSIM MATRIX

525

525

525

921

2560

2545

1001 